\title{
ESTUDO DA DUCTILIDADE DE AÇOS INOXIDÁVEIS DUPLEX DURANTE A CONFORMAÇÃO A QUENTE*
}

\author{
Everaldo da Silva ${ }^{1}$ \\ Thompson Junior Ávila Reis ${ }^{2}$ \\ Nilton José Lucinda de Oliveira ${ }^{3}$ \\ Cynthia Serra Batista Castro ${ }^{4}$ \\ Margareth Spangler Andrade ${ }^{5}$
}

\section{Resumo}

O objetivo deste trabalho foi estudar a fragilidade a quente de dois aços inoxidáveis duplex utilizando-se ensaios de torção. Ensaios de torção isotérmicos e em resfriamento contínuo, ambos com múltiplas deformações, foram realizados em corpos de prova de aços UNS S32304 e S31803. A caracterização microestrutural foi realizada por microscopia óptica e estudos sobre o equilíbrio de fases em temperaturas elevadas foram conduzidos utilizando simulação computacional. Nos ensaios em resfriamento contínuo, foi observada maior ductilidade no aço UNS 31803. Nos ensaios isotérmicos, foi constatada diminuição da ductilidade para os dois aços com a diminuição da temperatura do ensaio nos casos em que a fração volumétrica de austenita permaneceu constante.

Palavras-chave: Aço inoxidável duplex; Conformação a quente; Simulação computacional; Fração volumétrica de fases.

\section{STUDY OF DUPLEX STAINLESS STEEL DUCTILITY DURING HOT DEFORMATION}

\section{Abstract}

The hot brittleness of a duplex stainless steel was analyzed by hot torsion tests. Continuous cooling and isothermal torsion tests, both with multiples strains, were performed on UNS S32304 and S31803 steels. The microstructural characterization was performed by optical microscopy and phases equilibrium studies, in high temperature, were carried out by computational simulation. Continuous cooling results show a higher ductility for the UNS 31803. Isothermal results show a decrease in ductility for both steels with the decreasing of temperature when volumetric fraction of austenite is constant.

Keywords: Duplex stainless steel; Hot forming; Computational simulation; Volumetric fraction of phases.

1 Matemático, Mestrando, Programa de Pós-Graduação em Engenharia de Materiais, REDEMAT, UFOP, Ouro Preto, MG, Brasil.

2 Engenheiro da Computação, MSc. Pesquisador em Tecnologia, Instituto Senai de Inovação em Metalurgia e Ligas Especiais, Belo Horizonte, MG, Brasil.

3 Engenheiro Metalúrgico, MSc. Pesquisador em Tecnologia, Instituto Senai de Inovação em Metalurgia e Ligas Especiais, Belo Horizonte, MG, Brasil.

4 Engenheira Metalúrgica, Dr. Pesquisador em Tecnologia, Instituto Senai de Inovação em Metalurgia e Ligas Especiais, Belo Horizonte, MG, Brasil.

5 Física, Dr. Diretora e Pesquisadora em Tecnologia, Instituto Senai de Inovação em Metalurgia e Ligas Especiais, Belo Horizonte, MG, Brasil. 


\section{INTRODUÇÃO}

Os aços inoxidáveis duplex compõem uma classe de aços inoxidáveis que apresenta microestrutura bifásica constituída por frações aproximadamente iguais de ferrita e austenita [1]. Esta microestrutura característica lhe confere elevada resistência mecânica e à corrosão em muitos meios [2].

Devido à combinação de boas propriedades mecânicas e alta resistência à corrosão, esses aços são adequados para utilização em numerosas aplicações industriais tais como indústria de papel e celulose, exploração de petróleo e usinas nucleares [2-4].

Apesar de se tratarem de ligas de grande interesse da indústria, o seu processamento requer especial cuidado devido à existência de uma região de baixa ductilidade dentro da faixa de temperaturas de conformação a quente. A constituição bifásica de sua microestrutura tornam complexos os mecanismos de deformação e amaciamento durante a conformação a quente destas ligas [4].

A trabalhabilidade a quente da fase ferrita é melhor do que a da fase austenita. Isto por que a fase ferrita se recupera dinamicamente, aniquilando boa parte da fração de discordâncias geradas durante a deformação. Já a fase austenita pode amaciar por recristalização, gerando novos grãos a partir de regiões com alta densidade de discordâncias [3].

Em escala industrial, é comum o desenvolvimento de trincas nos cantos das placas que evoluem para serrilhamento das bordas e lascas nas bobinas durante 0 processo de laminação a quente, resultando em perda da produtividade e elevação do custo do produto [5].

A questão da trabalhabilidade a quente de aços inoxidáveis duplex tem sido explorada e diversos trabalhos, cujos objetivos estão relacionados a este fenômeno, estão disponíveis na literatura. Entre eles, destacam-se os trabalhos de Evangelista et al. [3] e Balancin et al. [4] que simularam fisicamente a conformação a quente de aços inoxidáveis duplex utilizando ensaios de torção. Ambos os autores tinham por objetivo explorar os mecanismos de deformação que ocorrem em um sistema bifásico e compreender o efeito, por exemplo, de parâmetros de processo e da composição química na trabalhabilidade a quente destes aços. Martin [5] investigou, entre outras coisas, os mecanismos de deformação a quente das fases ferrita e austenita de dois aços inoxidáveis duplex. Também é importante mencionar os trabalhos de Andrade et al. [6] e Gomes et al. [7] que investigaram, respectivamente, os efeitos da concentração de $\mathrm{S}$ e de $\mathrm{Nb}$ na trabalhabilidade a quente de um aço inoxidável duplex tipo UNS S32304.

Uma técnica adequada para se estudar a laminação a quente é através da simulação de laminação por ensaios de torção a quente, permitindo a reprodução dos processos termomecânicos envolvidos na conformação industrial [8-11].

Este trabalho teve como objetivo avaliar a fragilidade durante a conformação a quente de dois aços inoxidáveis duplex e estabelecer "janelas" de temperaturas mais favoráveis para evitar fraturas durante o processo de laminação a quente.

\section{MATERIAIS E MÉTODOS}

Foram estudados dois aços inoxidáveis duplex UNS S31803 e UNS S32304, fornecidos pela APERAM South America, processados industrialmente e recebidos na forma de chapas, denominados neste trabalho como 2205 e 2304 respectivamente. As amostras do aço 2205 foram provenientes de uma chapa obtida após a laminação no desbastador. O aço 2304 foi amostrado em produto acabado, 
laminado a quente, tratado termicamente e decapado. A tabela 1 apresenta a composição química das amostras dos aços inoxidáveis duplex 2205 e 2304.

Tabela 1. Composição química dos aços utilizados neste trabalho (\% em massa)

\begin{tabular}{ccccccccccc}
\hline Aço & $\mathbf{C}$ & $\mathbf{M n}$ & $\mathbf{S i}$ & $\mathbf{P}$ & $\mathbf{S}$ & $\mathbf{C r}$ & $\mathbf{N i}$ & $\mathbf{M o}$ & $\mathbf{C u}$ & $\mathbf{N}$ \\
\hline $\mathbf{2 2 0 5}$ & 0,015 & 1,87 & 0,30 & 0,03 & $3^{*}$ & 22,5 & 5,35 & 3,02 & 0,19 & $1563^{*}$ \\
\hline $\mathbf{2 3 0 4}$ & 0,019 & 1,35 & 0,39 & 0,03 & $4^{*}$ & 22,5 & 3,63 & 0,44 & 0,50 & $1128^{*}$ \\
\hline${ }^{*}$ ppm (parte por milhão) & & & & & & & &
\end{tabular}

Os ensaios de torção foram realizados em um equipamento de ensaios mecânicos INSTRON 1125, equipado com módulo de torção e célula de torque com capacidade de até $2000 \mathrm{kgf} . \mathrm{cm}$. Os ciclos térmicos foram realizados com auxílio de uma bobina de indução ligada a uma fonte com controlador programável, permitindo a execução de várias taxas de resfriamento ou aquecimento. Os ensaios foram realizados em atmosfera constituída de uma mistura de $\operatorname{Ar}$ e $\mathrm{N}$ para controle de oxidação e desnitretação. Uma interface permite a comunicação da máquina de ensaios com um microcomputador, sendo possível programar os passes de deformação a partir do microcomputador, bem como adquirir dados que permitem o levantamento de curvas de tensão equivalente em função da deformação equivalente.

Para avaliação da fragilidade durante a conformação a quente foram realizados ensaios de torção com múltiplas deformações em resfriamento contínuo e ensaios isotérmicos com múltiplas deformações. Em ambos, os corpos de prova foram aquecidos a $2^{\circ} \mathrm{C} / \mathrm{s}$, até $1200^{\circ} \mathrm{C}$ e mantidos nesta temperatura por 2 minutos. Nos ensaios com múltiplas deformações em resfriamento contínuo, após o aquecimento e o tempo de encharque, os corpos de prova foram resfriados a $1^{\circ} \mathrm{C} / \mathrm{s}$, aplicando-se deformações de 0,2 a cada $30^{\circ} \mathrm{C}$. Nos ensaios isotérmicos com múltiplas deformações, após o tempo de encharque, os corpos de prova foram resfriados a $1{ }^{\circ} \mathrm{C} / \mathrm{s}$ até a temperatura desejada, aplicando-se deformações de 0,3 em intervalos de 10s. Estes ensaios foram realizados nas temperaturas de 1000, 1050, 1100 e $1150^{\circ} \mathrm{C}$ e a primeira deformação foi aplicada após o corpo de prova ter ficado por 2 minutos na temperatura do ensaio.

Os corpos de prova de torção, ilustrados na Figura 1, foram usinados com eixo axial paralelo à direção de laminação.

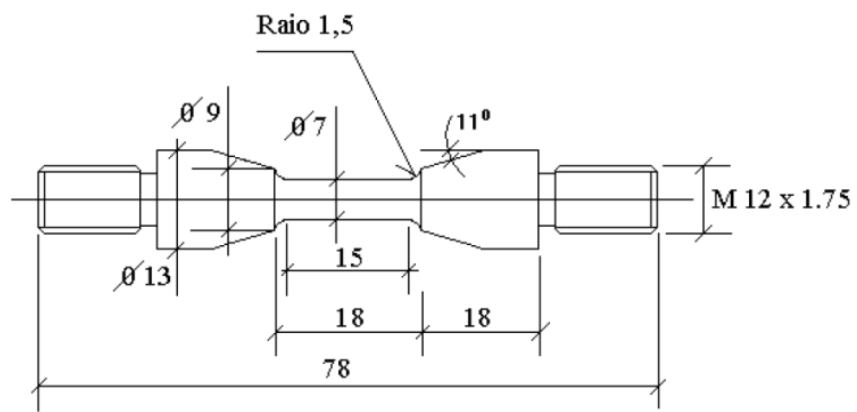

Figura 1. Corpo de prova para ensaio de torção a quente (dimensões em milímetros).

Para análises metalográficas, os corpos de prova foram cortados, após a realização dos ensaios de torção a quente, utilizando discos abrasivos, sendo todo o comprimento útil - $15 \mathrm{~mm}$ - embutido. O lixamento e o polimento foram realizados na seção longitudinal ao eixo do corpo de prova, para que as observações fossem feitas o mais próximo possível da sua superfície, uma vez que as deformações foram calculadas para a sua periferia. A preparação metalográfica foi feita por polimento convencional, utilizando-se lixas e suspensão de diamante e o reagente Beraha foi 
utilizado para revelar a microestrutura. A quantificação da fração volumétrica de ferrita e austenita foi realizada utilizando-se um sistema de aquisição e análise de imagem "Image-Pro" acoplado a um microscópio ótico.

Foram feitas simulações no Thermocalc utilizando o banco de dados TCFE7, com as composições químicas dos aços estudados neste trabalho, com o objetivo de determinar as temperaturas de equilíbrio de fases.

\section{RESULTADOS E DISCUSSÃO}

As curvas tensão equivalente em função da deformação equivalente, obtidas nos ensaios de torção com múltiplas deformações em resfriamento contínuo para os dois aços estudos estão ilustradas na Figura 2.

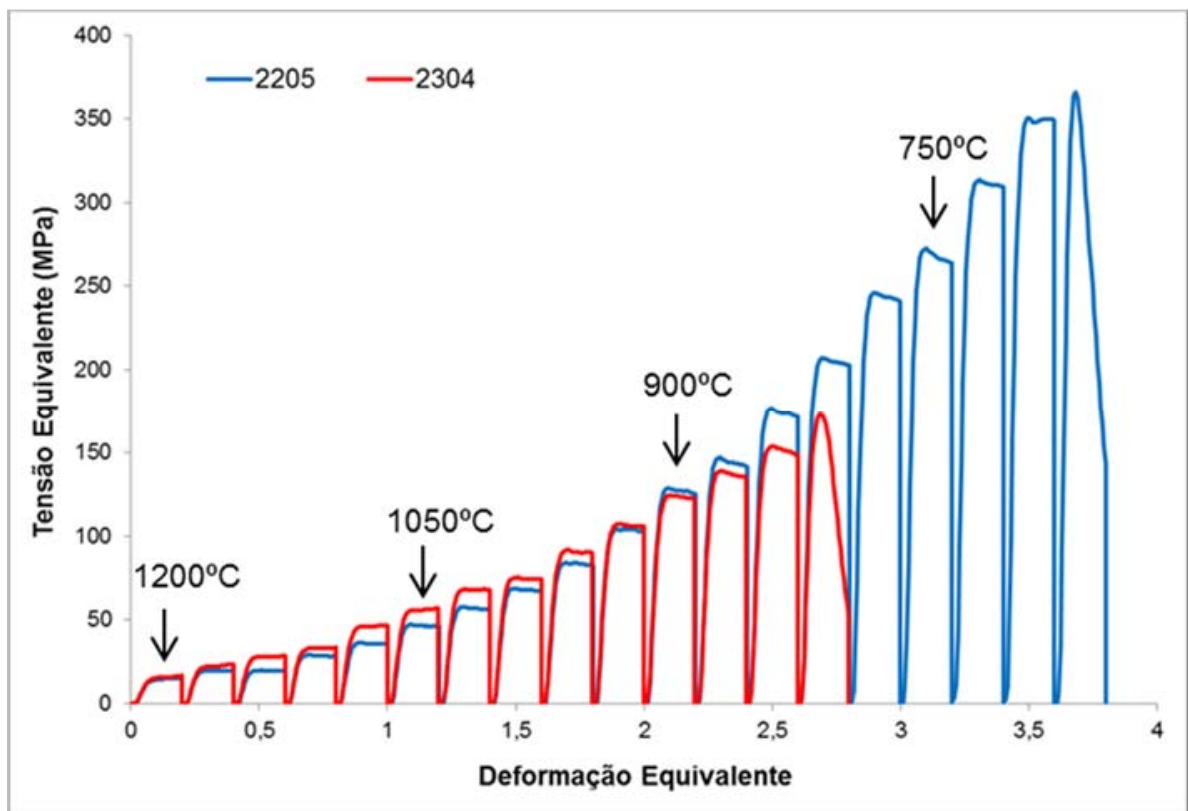

Figura 2. Tensão equivalente em função da deformação equivalente em resfriamento contínuo, a partir de $1200^{\circ} \mathrm{C}$, para os aços 2304 e 2205 .

Os resultados dos ensaios de torção a quente com múltiplas deformações em resfriamento contínuo, ilustrados na Figura 2, mostram que o aço 2205 suporta uma quantidade maior de deformação e em temperaturas mais baixas se comparado ao aço 2304. O aumento nos níveis de tensão de um passe para o seguinte está relacionado à diminuição de temperatura, com consequente aumento da resistência à deformação.

Nos ensaios isotérmicos com múltiplas deformações o comportamento de ambos os aços quanto à ductilidade foi similar em todas as temperaturas ensaiadas, conforme está ilustrado na Figura 3. Quanto à resistência à deformação, também foi observado comportamento similar para ambos os aços, exceto nas temperaturas de 1050 e $1150^{\circ} \mathrm{C}$. Na temperatura de $1050^{\circ} \mathrm{C}$ (Figura 3-b) o aço 2205 ofereceu resistência à deformação significantemente maior do que o aço 2304. Na temperatura de $1150^{\circ} \mathrm{C}$ (Figura 3-d) somente o aço 2205 apresentou encruamento nos passes iniciais. Fato que indica o efeito da presença da fase austenita influenciando no comportamento mecânico a quente da liga. Nesta temperatura o aço 2304 não apresentou encruamento. Este fato está relacionado com a ocorrência predominante de amaciamento dinâmico da fase ferrita. 


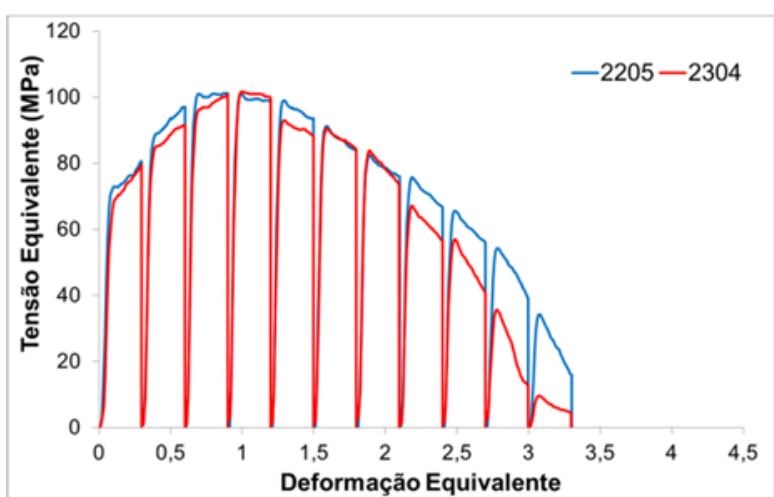

(a)

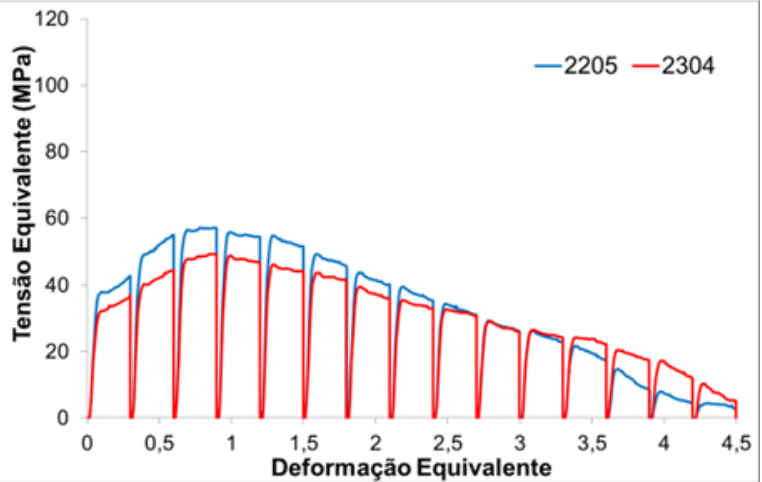

(c)

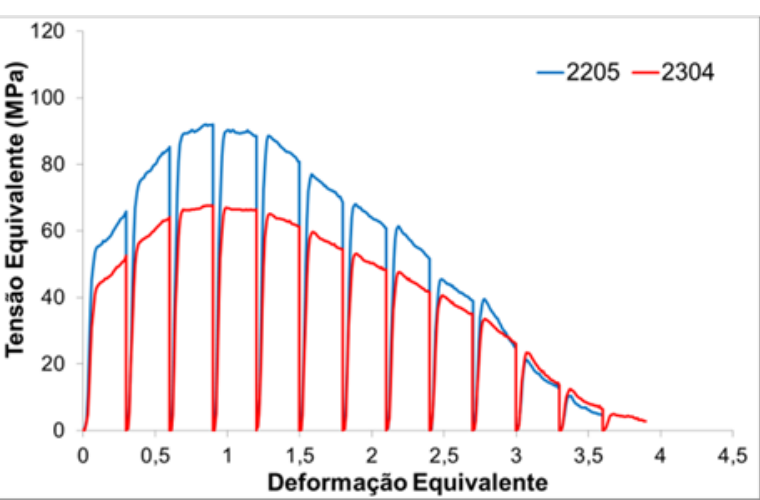

(b)

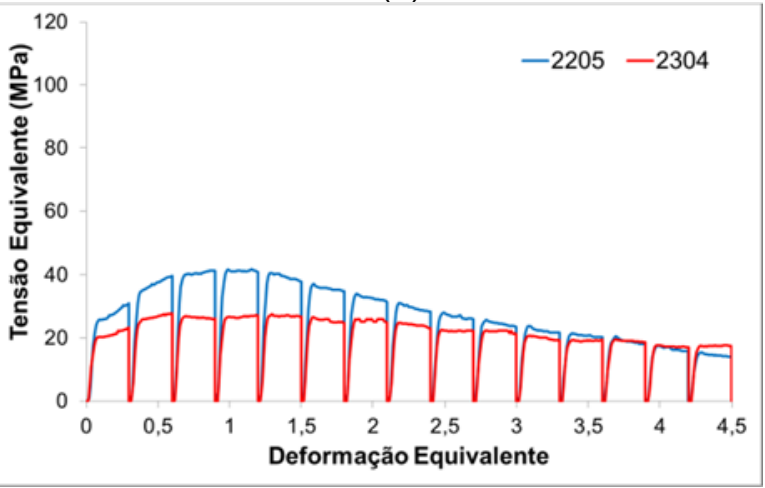

(d)

Figura 3. Curvas de tensão equivalente em função da deformação equivalente obtidos nos ensaios de torção a quente, isotérmicos com múltiplas deformações, nas temperaturas de (a) $1000{ }^{\circ} \mathrm{C}$, (b) $1050^{\circ} \mathrm{C}$, (c) $1100^{\circ} \mathrm{C}$ e (d) $1150^{\circ} \mathrm{C}$.

As frações volumétricas de austenita medidas nas amostras dos aços 2205 e 2304 no estado como recebido (CR) e após ensaios de torção isotérmicos estão apresentadas na Tabela 2.

Tabela 2. Fração volumétrica de austenita para os aços 2304 e 2205 nas condições como recebido e após ensaios de torção isotérmicos

\begin{tabular}{c|c|c|c|c|c}
\hline Aço & $\mathbf{C R}$ & $\mathbf{1 0 0 0}^{\circ} \mathbf{C}$ & $\mathbf{1 0 5 0}^{\circ} \mathbf{C}$ & $\mathbf{1 1 0 0}^{\circ} \mathbf{C}$ & $\mathbf{1 1 5 0}^{\circ} \mathbf{C}$ \\
\hline 2304 & 0,41 & 0,36 & 0,34 & 0,36 & 0,13 \\
\hline 2205 & 0,45 & 0,35 & 0,42 & 0,35 & 0,22 \\
\hline
\end{tabular}

Conforme pode ser observado na Tabela 2, a fração volumétrica de austenita é maior no aço 2205 do que no aço 2304 nas temperaturas de 1050 e $1150^{\circ} \mathrm{C}$. Este fato pode explicar a maior resistência à deformação observada no aço 2205 se comparado ao aço 2304 quando submetidos ao ensaio de torção isotérmico na temperatura de $1050^{\circ} \mathrm{C}$. A pequena fração volumétrica de austenita observada para o aço 2304 na temperatura de $1150^{\circ} \mathrm{C}$ indica que, nesta fração, esta fase não influenciou os mecanismos de amaciamento da liga. Conforme foi observado pelo formato da curva (Figura 3-d), ocorreu somente amaciamento dinâmico, característico da fase ferrita.

Nas Figuras 4 a 7, estão ilustradas imagens por microscopia óptica da microestrutura de ambos os aços após serem submetidos aos ensaios isotérmicos. 


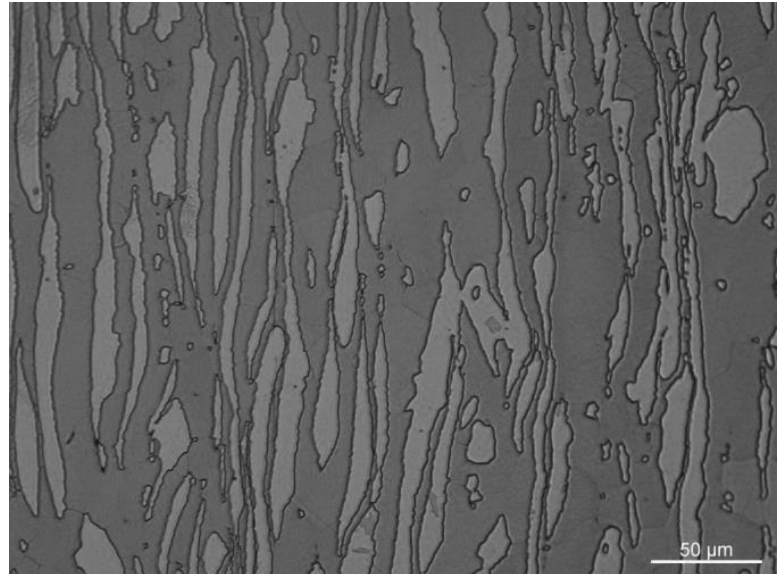

(a)

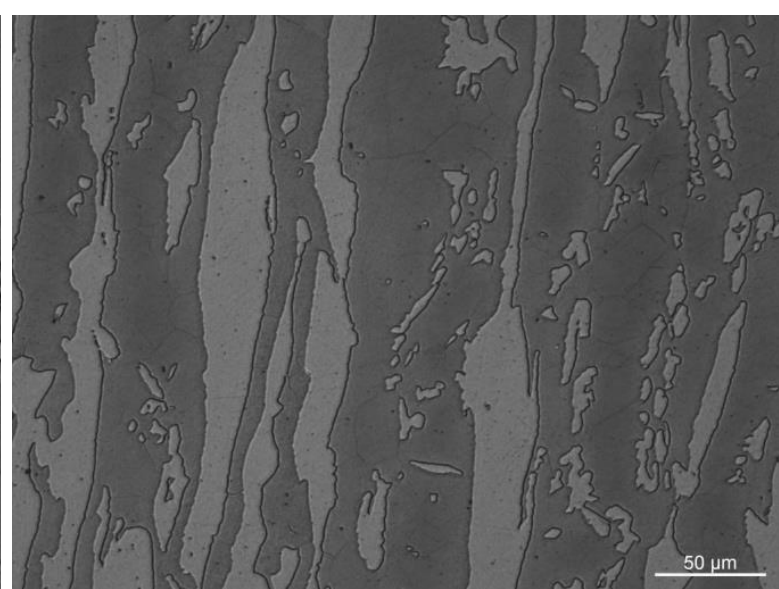

(b)

Figura 4. Imagens de microscopia óptica da microestrutura dos aços (a) 2304 e (b) 2205 após os ensaios de torção com múltiplas deformações a $1000^{\circ} \mathrm{C}$. Ataque: Beraha.

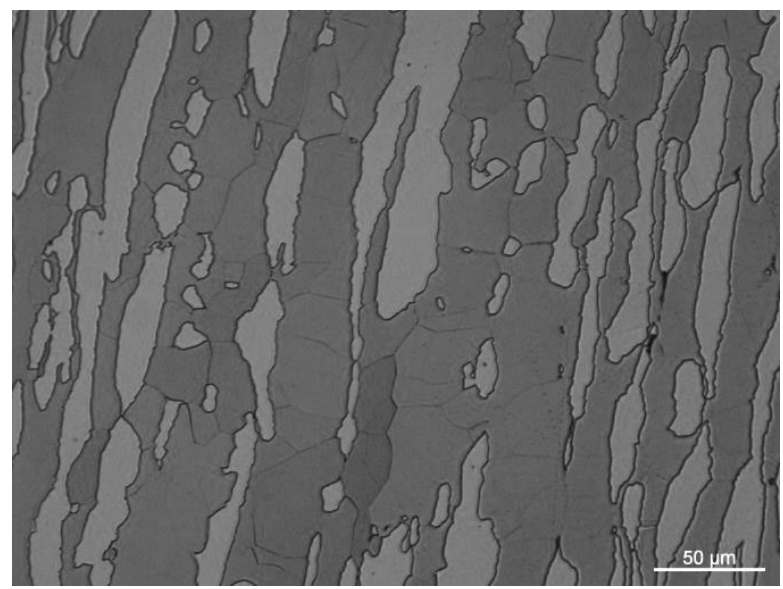

(a)

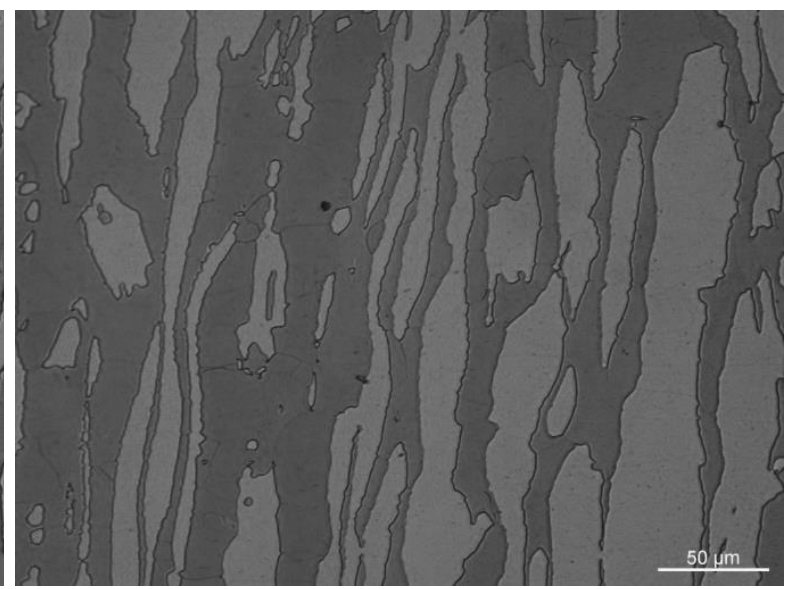

(b)

Figura 5. Imagens de microscopia óptica da microestrutura dos aços (a) 2304 e (b) 2205 após os ensaios de torção com múltiplas deformações a $1050^{\circ} \mathrm{C}$. Ataque: Beraha.

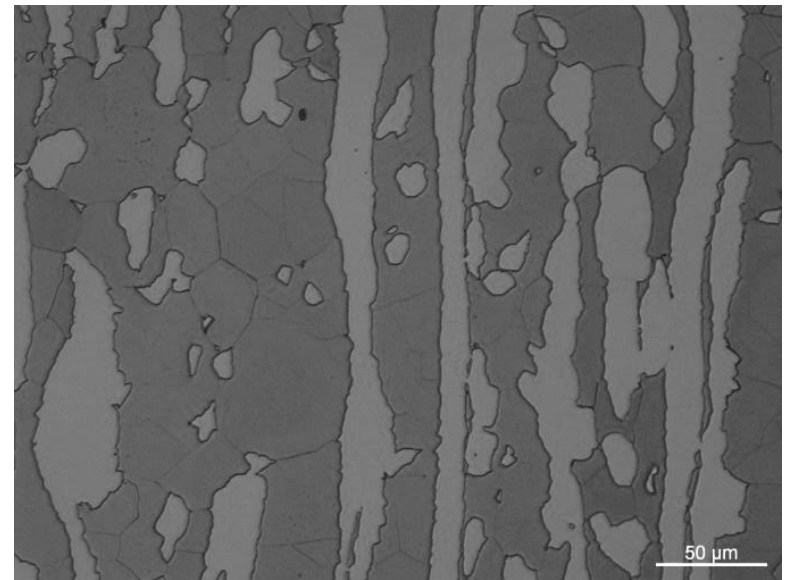

(a)

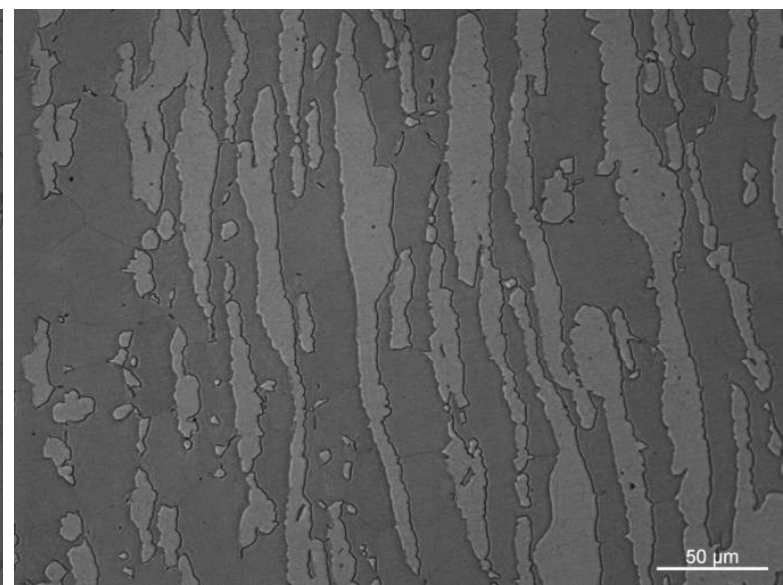

(b)

Figura 6. Imagens de microscopia óptica da microestrutura dos aços (a) 2304 e (b) 2205 após os ensaios de torção com múltiplas deformações a $1100^{\circ} \mathrm{C}$. Ataque: Beraha. 


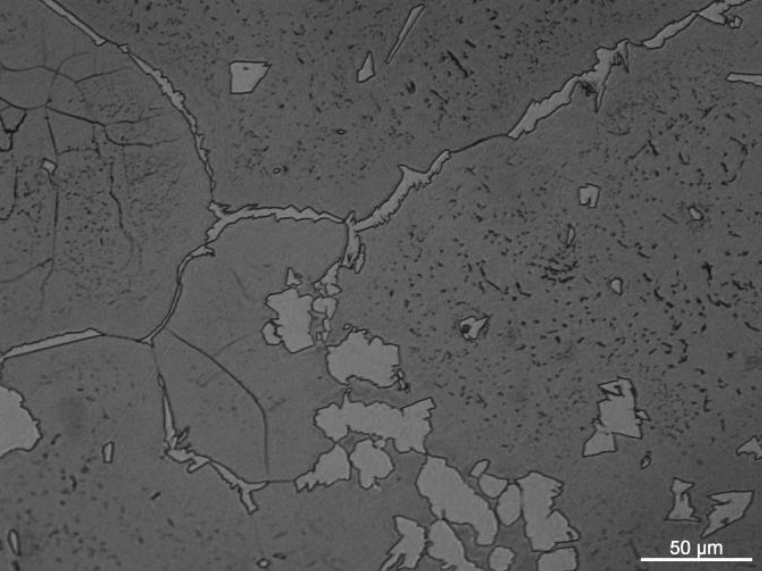

(a)

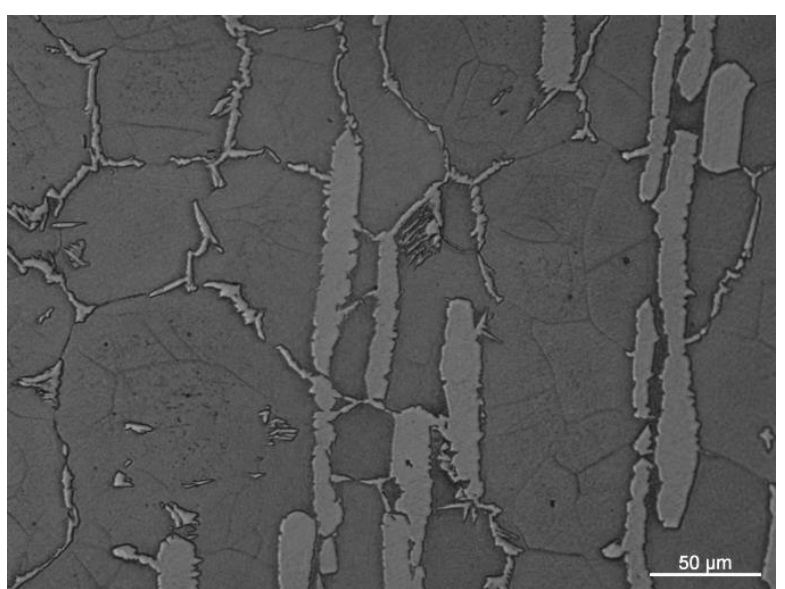

(b)

Figura 7. Imagens de microscopia óptica da microestrutura dos aços (a) 2304 e (b) 2205 após os ensaios de torção com múltiplas deformações a $1150^{\circ} \mathrm{C}$. Ataque: Beraha.

A Figura 8 ilustra os diagramas de fração de fase em equilíbrio em função da temperatura para os aços estudados, obtidos por meio da realização de simulações no software Thermocalc.

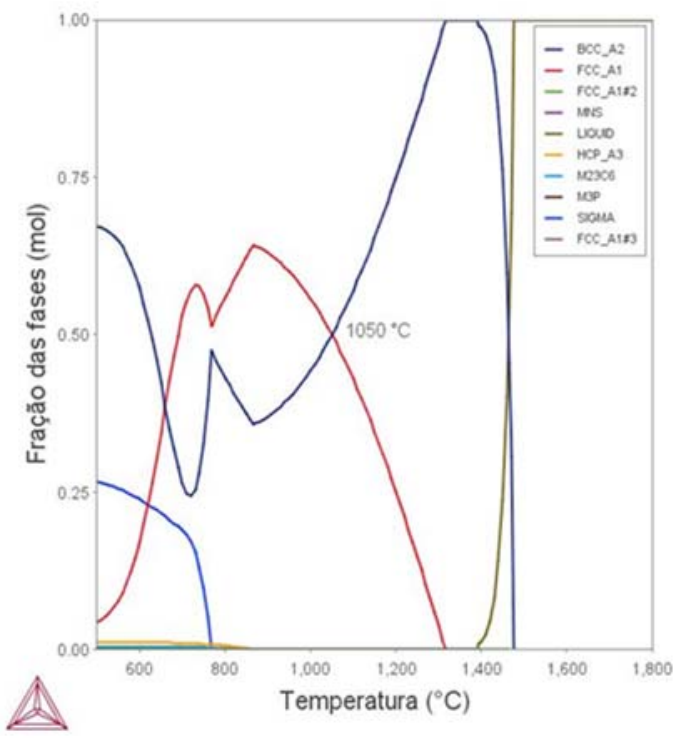

(a)

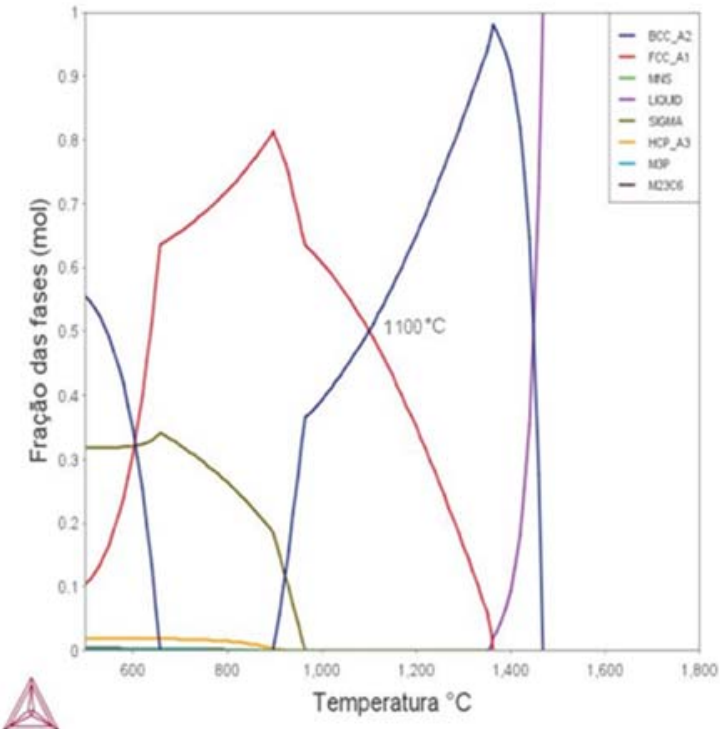

(b)

Figura 8. Diagramas de fração de fase em equilíbrio em função da temperatura obtidos por simulação no software Thermocalc para o aço (a) 2304 e (b) 2205.

Os resultados das simulações com as composições químicas dos aços estudados neste trabalho permitiram identificar a temperatura na qual se obtém a mesma fração volumétrica das fases ferrita e austenita. Esta temperatura é mais alta para o aço 2205 , da ordem de $1100^{\circ} \mathrm{C}$, quando comparada com a do aço 2304 , que foi da ordem de $1050^{\circ} \mathrm{C}$. Apesar do aço 2205 possuir maior teor de cromo, elemento que estabiliza a fase ferrita, ele também possui teores mais elevados de elementos estabilizadores da fase austenita, entre eles se destacam o nitrogênio, o níquel e o manganês. Este fato explica os resultados observados nas simulações computacionais.

Os resultados dos ensaios isotérmicos de torção, combinados com as análises metalográficas e com as simulações computacionais, indicaram que a resistência à 
deformação a quente de ambas as ligas estudadas e, consequentemente, a ductilidade estão relacionados principalmente com a fração volumétrica de austenita. Os resultados das análises metalográficas quantitativas indicaram que praticamente não ocorreu variação da fração volumétrica de austenita para ambas as ligas na faixa de temperatura entre 1000 e $1100^{\circ} \mathrm{C}$. Com exceção da fração volumétrica de austenita do aço 2205 ensaiado a $1050^{\circ} \mathrm{C}$ que foi da ordem de 0,42 , todas as demais amostras, de ambas as ligas, ensaiadas nessa faixa de temperatura, apresentaram fração volumétrica de austenita em torno de 0,35. Como a fração volumétrica da fase austenita no aço 2304 permaneceu constante durante os ensaios isotérmicos de torção entre 1000 e $1100^{\circ} \mathrm{C}$, o que se observou foi a redução da resistência à deformação da liga e aumento da ductilidade, à medida que a temperatura aumentou. O aço 2205 apresentou comportamento similar ao do aço 2304 nesta faixa de temperatura, exceto pelo fato de ter apresentado resistência significativamente maior do que o aço 2304 exatamente na temperatura de ensaio que a fração volumétrica foi maior. Como a resistência do aço 2205 foi maior do que a do aço 2304 na temperatura de $1050^{\circ} \mathrm{C}$ era esperado menor ductilidade. Ou ainda, esperava-se observar maior ductilidade do aço 2205 nas temperaturas em que a resistência deste aço foi similar à do aço 2304. Este fato indica que a ductilidade a quente destes aços não está relacionada somente à fração volumétrica das fases austenita e ferrita. Outros fatores como morfologia da fase austenita e a presença de elementos de liga que interferem no comportamento mecânico de cada uma das fases também podem estar atuando.

$\mathrm{Na}$ temperatura de $1150^{\circ} \mathrm{C}$ foi observada diminuição expressiva da fração volumétrica da fase austenita. Como efeito, ambas as ligas apresentaram redução na resistência à deformação e aumento da ductilidade. Além disso, observou-se maior redução da fração volumétrica de austenita no aço 2304. Resultado este em consonância com o observado nas simulações computacionais, que indicaram que o aço 2205 possui maior fração volumétrica de austenita nesta temperatura, se comparado ao aço 2304. A fração volumétrica de austenita da ordem de 0,13 no aço 2304 mudou o perfil da curva de fluxo do ensaio de torção, indicando que esta fase praticamente não influenciou os mecanismos de amaciamento, que foram predominantemente por recuperação dinâmica. Resultado observado somente para esta liga, nesta temperatura. Já a curva de fluxo para o aço 2205 ensaiado a $1150^{\circ} \mathrm{C}$ indicou que a fração volumétrica de austenita da ordem de 0,22 ainda é suficiente para influenciar nos mecanismos de deformação e amaciamento da liga. Fato observado pelo indicativo da curva de ter ocorrido encruamento da liga durante as duas primeiras deformações aplicadas neste ensaio.

\section{CONCLUSÃO}

- O aço 2205 apresentou maior ductilidade do que o aço 2304 no ensaio de torção a quente com múltiplas deformações em resfriamento contínuo.

- A fração volumétrica de austenita do aço 2304 não variou durante os ensaios de torção isotérmicos na faixa de temperatura entre 1000 e $1100^{\circ} \mathrm{C}$, observando-se somente a redução da resistência da liga, com aumento da ductilidade, em função do aumento da temperatura.

- Nos ensaios de torção isotérmicos nas temperaturas de 1000 e $1100^{\circ} \mathrm{C} o$ comportamento mecânico e a fração volumétrica de austenita do aço 2205 foram idênticos ao do aço 2304. Este fato pode indicar que as diferenças de 
composição química das ligas não influenciaram no seu comportamento mecânico à quente.

- No ensaio de torção isotérmico à $1050^{\circ} \mathrm{C}$ o aço 2205 apresentou maior resistência à deformação do que o aço 2304 devido à maior fração volumétrica de austenita.

- No ensaio de torção isotérmico à $1150^{\circ} \mathrm{C}$, com baixa fração volumétrica de austenita para o aço 2304, o mecanismo de amaciamento da liga predominante foi a recuperação dinâmica, característica da fase ferrita.

- As simulações computacionais realizadas com auxílio do software Thermocalc mostraram que o aço 2205 possui maior temperatura de equilíbrio entre as frações volumétricas das fases ferrita e austenita se comparado ao aço 2304.

\section{Agradecimentos}

Os autores agradecem a Aperam South América pelo fornecimento de amostras. Ao CNPq pela bolsa de produtividade, anos 2013-2015: Processo do Beneficiário: 134440/2013-7.

\section{REFERÊNCIAS}

1 Hättestrand M, Larsson P, Chai G, Nilsson J-O, Odqvist J. Study of Decomposition of Ferrite in a Duplex Stainless Steel Cold Worked and Aged at $450-500^{\circ} \mathrm{C}$. Materials Science and Engineering A. 2009; 499: 489-492.

2 Sahu JK, Krupp U, Ghosh RN, Christ H-J. Effect of $475^{\circ} \mathrm{C}$ Embrittlement on the Mechanical Properties of Duplex Stainless Steel. Materials Science and Engineering A. 2009; 508: 1-14.

3 Evangelista E, McQueen HJ, Niewczas M, Cabibbo M. Hot workability of 2304 and 2205 duplex stainless steels. Canadian Metallurgical Quarterly. 2004; 43(3): 339-354.

4 Balancin O, Hoffmann WAM, Jonas JJ. Influence of Microstructure on the Flow Behavior of Duplex Stainless Steels at High Temperatures, Metallurgical and Materials Transactions A. 2000; 31(A): 1353-1364.

5 Martin G. Hot Workability of Duplex Stainless Steels. Tese de doutorado, Université de Grenoble, 2011.

6 Andrade MS, de Oliveira NJL, Reis AG, de Oliveira TR. Influência do Enxofre na Trabalhabilidade a Quente de Aços Inoxidáveis Duplex. In: $68^{\circ} \mathrm{ABM}$ International Congress, July-30 August-2, (2013), Belo Horizonte, Brasil.

7 Gomes TE, de Oliveira NJL, Reis TJA, Andrade MS. Efeito do Nióbio na Trabalhabilidade a Quente do Aço Uns S32304. In: $51^{\circ}$ Rolling Seminar - Processes Rolled and Coated Products - International, October 28-31, (2014), Foz do Iguaçu, Brasil.

8 Boratto F, Yue S, Jonas JJ, Lawrence T. Projeto de Esquemas de Laminação Controlada Através de Ensaios de Torção Computadorizado. In: COLAM-ABM, Setembro de 1987, São Paulo.

9 Weiss I, Jonas JJ, Hunt PJ, Ruddle GE. Simulation of Plate Rolling on a Computerized Hot Torsion Machine and Comparison with Mill Results. In: Proceedings International Conference of Steel Rolling, Iron and Steel Institute of Japan, October 1980, Tokyo, Japan, 1225-1236.

10 Vilela JJ, Barbosa R. Prediction of Stress Strain Curves of Hot Deformed IF Austenite. ISIJ International. 2002; 42(3): 319-321.

11 Cho SH, Kang KB, Jonas JJ. Mathematical Modeling of the Recrystallization Kinetics of $\mathrm{Nb}$ Microalloyed Steels. ISIJ International. 2001; 41(7): 766-773. 